\title{
Functional Cardiological Changes Resulting from Thoracoscopic Thoracic Sympathectomy: Systematic Review
}

\author{
Juliano Mendes de Souza ${ }^{1,2 *}$, Henrique Lechinski Rodrigues², Jean Borges Curimbaba², \\ Daniele Bruch ${ }^{2}$
}

\footnotetext{
${ }^{1}$ Department of Surgery, Thoracic Surgery Unit, Hospital de Clínicas Complex, Federal University of Parana, Curitiba, Brazil ${ }^{2}$ Faculdades Pequeno Príncipe, Curitiba, Brazil

Email: ^julianomendes.dr@gmail.com
}

How to cite this paper: de Souza, J.M., Rodrigues, H.L., Curimbaba, J.B. and Bruch, D. (2021) Functional Cardiological Changes Resulting from Thoracoscopic Thoracic Sympathectomy: Systematic Review. Surgical Science, 12, 302-312.

https://doi.org/10.4236/ss.2021.128031

Received: June 18, 2021

Accepted: August 27, 2021

Published: August 30, 2021

Copyright ( 2021 by author(s) and Scientific Research Publishing Inc. This work is licensed under the Creative Commons Attribution International License (CC BY 4.0).

http://creativecommons.org/licenses/by/4.0/

\begin{abstract}
Hyperhidrosis is a condition resulting from a systemic sympathetic hyperactivity. The gold standard treatment is the resection or surgical ablation of the paravertebral sympathetic chain: the endoscopic thoracoscopic sympathectomy (ETS). Non-cardiac thoracic surgeries carry a considerable incidence of pathological postoperative cardiac events, raising attention to possible worsen cardiac functional capacity after the resection of a pair of thoracic sympathetic ganglia. The aim of this study is to investigate literature evidences of postoperative cardiovascular functional changes on patients submitted to ETS as treatment for hyperidrosis. This is a systematic review of the literature. Clinical studies published between January 1999 and April 2019 were analyzed. The PICO strategy was used to construct the question of systematic reviews research. The process of selecting articles was organized according to PRISMA Diagram. The search in electronic databases resulted in seven articles, of which one was excluded for being out of scope of the research, leaving six articles. All studies showed a pattern of heart rate (HR) reduction after endoscopic thoracic sympathectomy. It was suggested a relation between the extension of the procedure and the presence of cardiac functional alterations. There was an improvement in myocardial physical conditioning and maintenance of functional capacity. To elucidate the real mechanisms involved in the maintenance of myocardial function, and even its improvement, it is necessary to develop further studies that directly evaluate them.
\end{abstract}

\section{Keywords}

Hyperhidrosis, Sympathectomy, Thoracoscopic, Heart Rate, Heart Function Tests 


\section{Introduction}

Hyperhidrosis is a condition resulting from sympathetic hyperactivity of the sweat glands, causing focal excessive sweating, mainly palmar and axillary. It affects about $1 \%$ of the Western population, with equal prevalence in both genders. Hyperstimulation of the sweat glands may be secondary to obesity, hyperthyroidism, menopause and psychiatric disorders, the resolution of which consists in the treatment of the underlying or primary disease. The treatment of primary hyperhidrosis may be conservative, through drugs and psychotherapy, or surgical, considered definitive. The gold standard treatment is endoscopic thoracoscopic sympathectomy (ETS) [1] [2].

The ETS consists of the endoscopic surgical approach of the paravertebral sympathetic chain at the level of T3(G3) or T4(G4) [2]. When performed on T3(G3), it presents greater efficacy of the procedure, yet higher rates of compensatory hyperhidrosis. When at T4(G4), the compensation index is lower, becoming best recommended. However, despite being the gold standard, patient's hands can remain a little damp. The interruption of the sympathetic chain can be performed through transection, resection, ablation with cautery or division with harmonic scalpel.

A considerable part of the patients submitted to this procedure present transient postoperative functional modifications well established in the literature. However, when dealing with changes in cardiac function, there is a limited number of studies, in which the alterations were evaluated through functional tests [3].

The evaluation of the functional capacity of the cardiopulmonary system can be done through direct and indirect tests, such as the ergospirometric test and the 6-minute walk test, respectively [4] [5]. The studies are based on the measurement of maximum oxygen consumption, the most important parameter of physical conditioning and most objective for establishing prognosis for cardiovascular diseases, as it reflects the capacity of absorption, transport and oxygen consumption [6].

Due to the increase in the number of patients submitted to ETS, the importance of scientific knowledge about functional changes in the postoperative period of this procedure increases, raising questions about the existence of cardiac functional alterations, what they would be and their impact on myocardial functional capacity. This study aims to investigate the evidence in the literature regarding cardiovascular functional alterations present in the postoperative period of patients submitted to ETS for the treatment of primary hyperhidrosis.

\section{Methods}

This is a systematic review of the literature. This type of study follows the structure of an original study and its elaboration requires a methodical, explicit and reproducible design, being a guide for the development of new research and synthesizing the evidence described in the literature [7]. 
Clinical studies published between January 1999 and April 2019 were analyzed. The PICO strategy was used to construct the question of systematic reviews research: the population studied was of patients submitted to endoscopic thoracoscopic sympathectomy by primary hyperhidrosis; the intervention, the endoscopic thoracoscopic sympathectomy; the control, the evaluation of preoperative cardiac function, and the outcome, the evaluation of postoperative cardiac function and its comparison with the previous evaluation [8].

The sources of search for articles were the PubMed, Scielo and LILACS databases. The search terms used in the search in the database were (hyperhidrosis); (sympathectomy); (thoracoscopic); (heart rate); (heart function tests).

Two reviewers independently read the six articles included in this systematic review. The second sample was categorized: title, authors, journal and year, as presented in Table 1 and the categorization of the sample according to: research question, objectives, method and number of participants, as shown in Table 2. Each selected relevant data to answer the research question, so a second reading was performed for joint decision on which data would be collected with divergence resolution from an independent third reviewer.

The assessment of the bias risk was performed through the critical reading of clinical studies, seeking a detailed description of the methodology used. The included studies were conducted with approval in ethics committees, randomization, conducted based on predefined protocols, thus reducing the possibility of bias.

Table 1. Characteristics of included trial in the review: by title, autors, periodic and year.

\begin{tabular}{ll}
\hline Title & Authors \\
\hline $\begin{array}{l}\text { Cardiac Autonomic Changes After Thoracic } \\
\text { Sympathectomy: A Prospective, Randomized }\end{array}$ & $\begin{array}{l}\text { Alfonso Fiorelli, Giovanni Messina, Paolo Chiodini, } \\
\text { Saveria Costanzo, Andrea Viggiano, Marcellino Monda, } \\
\text { Study }\end{array}$ \\
Giovanni Vicidomini and Mario Santini
\end{tabular}

T2-T3 sympathectomy versus sympathectomy for essential palmar hyperhidrosis: comparison of effects on cardio-respiratory function

Long-term Cardiopulmonary function after thoracic sympathectomy: Comparison between the conventional and simplified techniques

Thoracic sympathectomy and cardiopulmonary responses to exercise

Endoscopic Thoracic Sympathectomy Suppresses Baroreflex Control of Heart Rate in Patients with Essential Hyperhidrosis

Thoracic sympathectomy: effects on hemodynamics and baroreflex control
Thoracic sympathectomy: effects on hemodynamics and baroreflex control

European journal of

Cardio-Thoracic surgery

Miguel Angel Ponce González, MD, Gabriel Juliá Serdá, MD, The journal of Thoracic Pedro Rodriguez Suarez, MD, Gregorio Perez-Penãte, MD, Jorge Freixinet Gilart, MD, Pedro Cabrera Navarro, MD and Cardiovascular 2010 Surgery

Omri Inbar, D. Leviel, I. Shwartz, H. Paran, B. J. Whipp

European Journal of Applied physiology

Yurie T. Kawamata, MD, Tomoyuki Kawamata, MD, Keiichi Omote, MD, Eiji Homma, MD, Tatsuo Hanzawa, MD,

Anesthesia and analgesia
René Kingma Ben J. TenVoorde Gert Jan Scheffer John M. Karemaker Albert J. C. Mackaay Karel H. Wesseling Jaap J.de Lange
Clinical autonomic

research 
Table 2. Characteristics of included trial in the review: by question, objective, study design and sample.

\begin{tabular}{|c|c|c|c|}
\hline Question & Objective & Study design & Sample \\
\hline $\begin{array}{l}\text { Can cardiac autonomic changes be associated with } \\
\text { different degrees of sympathetic resection in the } \\
\text { management of essential palmar hyperhidrosis? }\end{array}$ & $\begin{array}{l}\text { To determine cardiac autonomic changes resulting from sympathetic } \\
\text { resection in the management of essential palmar hyperhidrosis and } \\
\text { identify their differences due to the degree of resection. }\end{array}$ & Clinical trial & 60 \\
\hline $\begin{array}{l}\text { Is the extent of sympathectomy related to the } \\
\text { degree of cardiorespiratory changes after surgery? }\end{array}$ & $\begin{array}{l}\text { Determine cardiorespiratory changes after endothoracic sympathetic } \\
\text { denervation and its correlations with the extent of denervation }\end{array}$ & Clinical trial & 45 \\
\hline $\begin{array}{l}\text { Does reducing the extent of sympathic transection } \\
\text { modify long-term cardiopulmonary function? Are } \\
\text { such changes correlated with the extent and height } \\
\text { of sympathectomy? }\end{array}$ & $\begin{array}{l}\text { To evaluate whether the reduction in the extent of sympathic } \\
\text { transection modifies long-term cardiopulmonary function and } \\
\text { determine whether such changes are correlated with the extent and } \\
\text { height of sympathectomy. }\end{array}$ & Clinical trial & 32 \\
\hline $\begin{array}{l}\text { What are the effects of ETS on the treatment of } \\
\text { axillary hyperhidrosis on physiological responses at } \\
\text { rest and during submaximal and maximal exertion? }\end{array}$ & $\begin{array}{l}\text { To study the effect of ETS on the treatment of axillary hyperhidrosis } \\
\text { on physiological responses at rest and during submaximal and } \\
\text { maximal exertion. }\end{array}$ & Clinical trial & 10 \\
\hline $\begin{array}{l}\text { What is the influence of ETS on baroreflex responses } \\
\text { to hypertensive and hypotensive tests under low-dose } \\
\text { anesthetic influence? }\end{array}$ & $\begin{array}{l}\text { Examine the influence of ETS on baroreflex responses to } \\
\text { hypertensive and hypotensive tests under low-dose anesthetic } \\
\text { influence. }\end{array}$ & Clinical trial & 40 \\
\hline $\begin{array}{l}\text { Changes in hemodynamic homeostasis and systemic } \\
\text { blood pressure control after thoracoscopic } \\
\text { sympathectomy on T2-T4 }\end{array}$ & $\begin{array}{l}\text { Evaluate changes in hemodynamic homeostasis and systemic blood } \\
\text { pressure control after thoracoscopic sympathectomy on } \mathrm{T} 2-\mathrm{T} 4\end{array}$ & Clinical trial & 12 \\
\hline
\end{tabular}

\section{Results}

The search in electronic databases resulted in seven articles, of which one was excluded for escaping the scope of the research, leaving six articles. The six articles were fully evaluated and were considered appropriate to enter this systematic review, based on inclusion criteria. Figure 1 presents the process of selecting articles organized according to PRISMA Diagram [9].

The six studies included in this systematic review, [10]-[15], showed a pattern of heart rate (HR) reduction after endoscopic thoracic sympathectomy. This data was evaluated by different methods and different periods of time according to Table 3.

In the reference [10], the evaluation occurred 3 days before the procedure and after 3 to 4 weeks after the procedure, through postural and breathing tests, with measurement by electrocardiogram and noninvasive monitoring of systemic blood pressure. Data were obtained and compared between supine and orthostatic positions. The author pointed out important hemodynamic responses after the procedure. Orthostasis increased normal HR, duplication of systolic volume reduction and duplication of peripheral vascular resistance increase. The only autonomic parameter with significant alteration was the reduction of the maximum and minimum $\mathrm{HR}$ variation after getting up. With greater significance, reduction in resting heart rate, increase in systolic volume by $30 \%$ and reduction in peripheral vascular resistance by $25 \%$ were observed. Data found to have no statistical significance were the reduction in blood pressure at rest, increased cardiac output and increased baroreflex sensitivity, particularly orthostasis. There was no change in the HR variation pattern related to inspiration and expiration, nor in parasympathetic activity. 


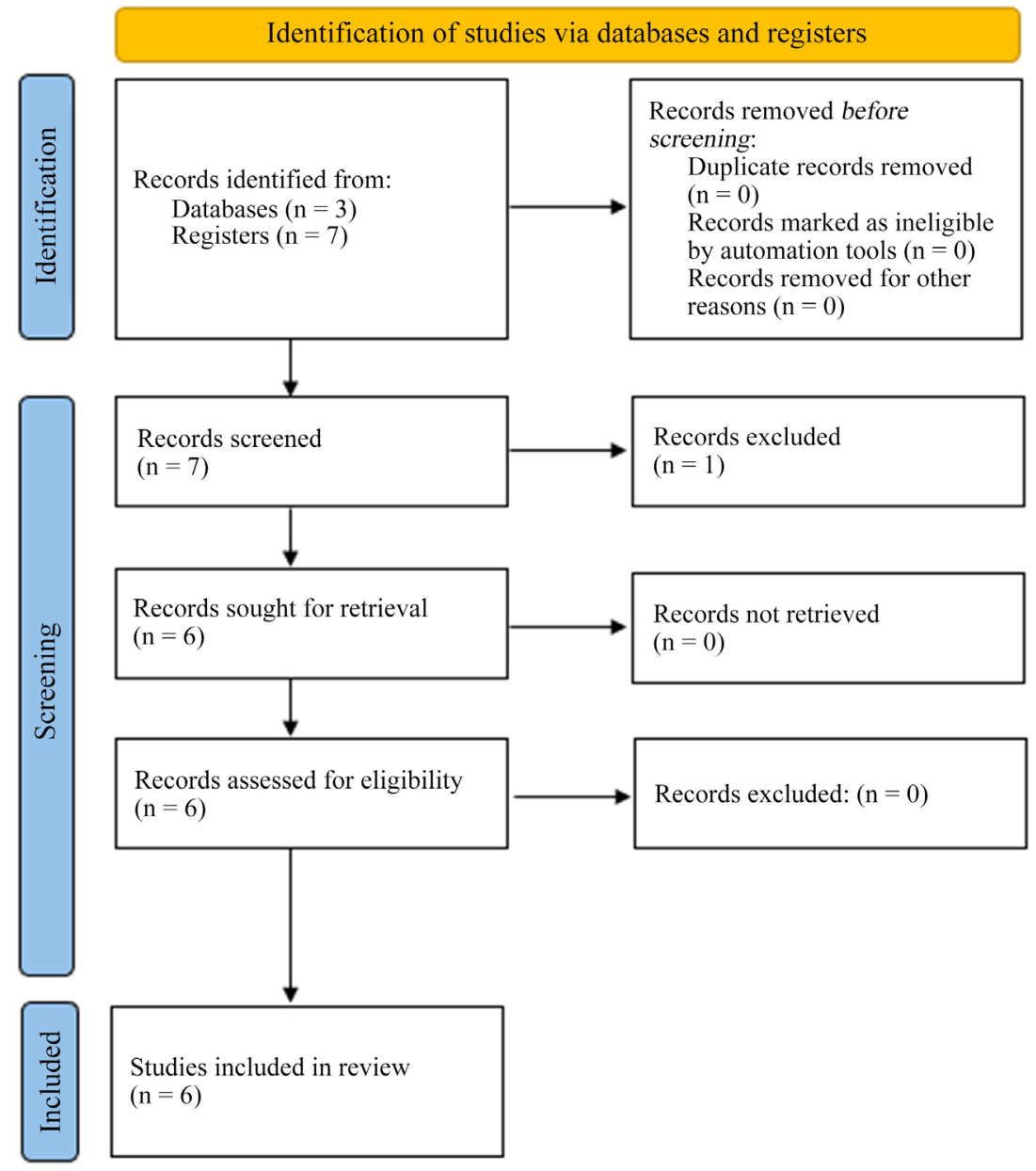

Figure 1. PRISMA flow diagram. ${ }^{*}$ Search terms: (hyperhidrosis); (sympathectomy); (thoracoscopic); (heart rate); (heart function tests).

Table 3. Characteristics of included trial in the review: by test, results and conclusion. ${ }^{\text {a }}$

\begin{tabular}{|c|c|c|}
\hline Test & Results & Conclusion \\
\hline Holter & $\begin{array}{l}28 \text { patients underwent sympathectomy and } 29 \text { underwent } \\
\text { sympathotomy. In both groups we found increased vagal } \\
\text { activity and a significant decrease in adrenergic activity through } \\
\text { reduced heart rate. These alterations were more evident in the } \\
\text { group that underwent sympathectomy. }\end{array}$ & $\begin{array}{l}\text { Endoscopic thoracic sympathectomy caused a shift of } \\
\text { sympathovagal balance toward para-sympathetic tone that } \\
\text { seems to be associated with the extent of denervation }\end{array}$ \\
\hline Ergometry & $\begin{array}{l}21 \text { patients in each group (sympathectomy and sympathotomy) } \\
\text { completed the study. In the group that underwent } \\
\text { sympathotomy, no significant cardiac alterations were found, } \\
\text { in the group that underwent sympathectomy, there was a } \\
\text { significant reduction in heart rate at rest and in exercise. These } \\
\text { changes remained after } 6 \text { months of the procedure. }\end{array}$ & $\begin{array}{l}\text { Sympathectomy may result in a disturbance of bronchomotor } \\
\text { tone and cardiac function. Such changes remained at a } \\
\text { sub-clinical level and seemed directly correlated with the } \\
\text { extension of denervation. }\end{array}$ \\
\hline Ergometry & $\begin{array}{l}\text { Pulmonary function tests show a significant reduction in FF1, } \\
\text { FeF } 25 \% \text { - } 75 \% \text { of vital capacity in both groups. Heart rate at } \\
\text { rest and after maxima exercise also decreased significantly in } \\
\text { both groups. Despite all the alterations, the patients remained } \\
\text { asymptomatic. We did not find differences between the } \\
\text { sympathectomy and sympathotomy groups. }\end{array}$ & $\begin{array}{l}\text { Simplified and conventional thoracic sympathectomy resulted } \\
\text { in a long-term reduction in FEV1, FEF } 25 \%-75 \% \text {, DLCO, and } \\
\text { resting and maximal heart rate, as well as a mild but } \\
\text { significant increase in airway resistance in the conventional } \\
\text { thoracic sympathectomy group, without any clinical } \\
\text { consequence to the patient. These changes were unrelated to } \\
\text { the level of transection of the thoracic sympathetic chain. }\end{array}$ \\
\hline
\end{tabular}




\section{Continued}

\begin{tabular}{|c|c|c|}
\hline Ergometry & $\begin{array}{l}\text { There was no significant difference in exercise tolerance. Only } \\
\text { heart rate, rate pressure product and oxygen pulse were } \\
\text { significantly altered by surgical procedure. Heart rate } \\
\text { significantly decreased at rest, submaximal effort, and } \\
\text { maximally exertion. As there were no significant changes in } \\
\text { VO2, this resulted in a significant increase in oxygen pulse. The } \\
\text { rate pressure product has undergone significant reduction. }\end{array}$ & $\begin{array}{l}\text { Thoracoscopic sympathectomy does not seem to influence } \\
\text { exercise capacity, as it produces responses in the } \\
\text { cardiovascular and/or muscular system. The finding of heart } \\
\text { rate reduction is compatible with other studies. Further } \\
\text { studies are needed to determine the mechanism responsible } \\
\text { for unaffected work capacity. }\end{array}$ \\
\hline $\begin{array}{l}\text { Pharmacological } \\
\text { tests }\end{array}$ & $\begin{array}{l}\mathrm{n} \text { the hypertensive test, sympathectomy significantly reduced } \\
\text { baroreflex sensitivity in all patients. } 1 \text { patient in this group } \\
\text { presented complete inhibition of the baroreflex. In the } \\
\text { hypotensive test, a reduction in baroreflex sensitivity was also } \\
\text { found, and } 9 \text { of the } 21 \text { patients had complete inhibition. }\end{array}$ & $\begin{array}{l}\text { Sympathectomy suppressed baroreflex heart rate control in } \\
\text { hypertensive and hypotensive tests in patients with palmar } \\
\text { or axillary hyperhidrosis under anesthesia in small doses. } \\
\text { A simpatovagal imbalance has been reported with a } \\
\text { parasympathetic balance predominance. Further studies are } \\
\text { needed. }\end{array}$ \\
\hline
\end{tabular}

a. All studies adopted $\mathrm{p}<0.05$ as significance level.

Reference [11] evaluated 10 individuals through ergospirometry, performed 3 weeks before ETS and 2 months later, evaluating them at 3 different times: rest, submaximal and maximal exertion. A reduction in HR was found in all 3 moments of the postoperative test, besides significant increase in the oxygen pulse and a significant compensatory decrease in the rate pressure product for maintenance of Maximum Oxygen Uptake. There was no change in exercise tolerance or body parameters of individuals, such as weight and BMI.

Reference [12] evaluated the cardiopulmonary function of 32 patients through ergospirometry tests performed before the procedure and 1 year postoperatively. The patients were divided into 2 groups: the first, submitted to conventional ETS, had 18 patients, while the second, with 14 patients, underwent simplified ETS. The author found a significant reduction in HR at rest and at maximus effort in both groups, with no differences according to the level of resection. The study did not evaluate other variables related to the cardiovascular system such as Blood Pressure, Cardiac Output, Systolic Volume.

Reference [13] used ergospirometry to evaluate both cardiac and respiratory functions. The tests were performed before the procedure, 2 weeks later and 6 months later, using 2 groups: one underwent conventional ETS and the other went through simplified ETS. The first group experienced a significant reduction in heart rate at rest and during physical activity after 2 weeks of the procedure and maintained at evaluation after 6 months. The second group did not present significant cardiovascular, ventilatory, metabolic or electrocardiographic alterations. Suggesting a relation between the extension of the procedure and the presence of cardiac functional alteration. Despite the differences found between the groups, there was no reduction in functional capacity in any group, and all patients were able to complete the tests. ETS did not cause significant electro- 
cardiogram alteration or metabolic parameters.

Another study [14] again compared patients who underwent conventional and simplified sympathectomy. The groups were evaluated through 24-hour Holter performed 7 days before the procedure, 24 hours after, 1, 3 and 6 months after. A reduction in resting heart rate was identified with consequent increase in systolic volume, as well as an increase in HR variability. No patient presented cardiac symptoms after the procedure and all alterations found were within the parameters of normality.

Reference [15] in turn, used immediate preoperative and postoperative hypertensive and hypotensive tests, with patients under sedation, through intravenous administration of phenylephrine or nitroglycerin. The group using phenylephrine to increase systemic blood pressure was composed of 19 patients, while the group using nitroglycerin to reduce systemic blood pressure consisted of 21 patients. To reduce the bias resulting from the possible effects of anesthesia in these patients, short-term anesthetic drugs were used. In this study, no change in heart rate or systemic blood pressure resulting from the procedure was proven, however, a significant reduction in the baroreflex measured was confirmed through the regression curve of the R-R interval on the electrocardiogram and through systolic blood pressure obtained through a radial arterial catheter. The reduction of baroreflex may also have been underestimated by the use of anesthetic drugs.

\section{Discussion}

The difference of results in cardiac functional alterations resulting from the extension of the procedure is controversial. Reference [12] demonstrated a reduction in heart rate both at rest and during exercise by comparing the pre and postoperative evaluations, regardless of the length of the procedure.

The changes found are similar to the effects of the use of beta-blockers [10] [11] [13]. A possible mechanism responsible for changing heart rate is the blockage of sympathetic response to baroreceptors [11] [15]. A pressure increase would be responsible for the stimulation of baroreceptors, which would activate neurons of the of the solitary tract nucleus, responsible for exciting parasympathetic preganglionic neurons, determining increased vagal activity and heart rate drop. Another mechanism defended by [13] would be the very reduction of sympathetic stimulus both in the myocardium and in its negative feedback in the vagal system. In this case the reduction in heart rate should be more evident during exercise and less relevant to rest.

Reference [15] demonstrates results compatible with decreased baroreflex sensitivity. A possible bias is the use of drugs that act by suppressing the baroreflex involved in HR control during the test. However, such drugs would be responsible for changing the baroreflex test before ETS, not after. In some cases of resection at the T2-T3 level, there was complete suppression of the baroreflex, suggesting the existence of a relation between the level of suppression and the ex- 
tension of the procedure. The impact of this change may be an unpredictable cardiovascular response to the reduction or increase in blood pressure.

The study [14] found a change in the sympathovagal balance with greater participation of parasympathetic tone, resulting in increased heart rate variability, which acts as a protective factor against conditions such as intractable angina, ventricular tachycardia and arrhythmias associated with long QT segment, thus suggesting ETS as a possible treatment for such conditions.

Another alteration found in the postoperative period of ETS [10] was an improvement in the expected increase in peripheral resistance and greater reduction in systolic volume when patients were up, as well as the absence of increased HR at work, directly dependent on sympathetic stimulus. Peripheral resistance at rest, in turn, decreased by $25 \%$, resulting in an elevation in cardiac output, minimizing the expected reduction of systemic blood pressure.

The maintenance of respiratory and metabolic parameters such as Wmax and $\mathrm{VO}_{2}$ peak in submaximal exercise, demonstrating absence of functional alteration, despite the reduction of heart rate, can be justified by the suppression of the adrenergic stimulus by the ETS, whose consequences can cause improvement in blood flow to the heart and muscles [13]. This mechanism should be evaluated with caution, since the author only suggested its existence, not directly evaluating the arteriovenous difference and cardiac output. In addition, the probable increase in the ejection fraction (14) stands out, maintaining heart function despite the HR drop, since the reduction in heart rate would predispose to a decrease in cardiac output unless there was a compensatory increase in systolic volume.

Less likely, however possible, is the occurrence of improvement in oxygen uptake capacity by myocardial muscles [11]. As a support for this statement, can be mentioned Frank-Starling's physiological mechanism: a reduction in heart rate without a compensatory increase in the ejection fraction would result in a reduction in cardiac output, which in turn would be responsible for lower tolerance to exercise, unless the muscle's oxygen uptake capacity is improved. Another option is the selective increase, as already mentioned, of blood flow to the heart and muscles. This hypothesis is validated in the studies in question, since there was no decrease in exercise tolerance despite the clear reduction in heart rate [11] [14], in addition to the reduction of the rate pressure product due to ablation and increased oxygen pulse, demonstrating an improvement in the physical conditioning of the heart [11] [13].

Considering the maintenance of diastolic blood pressure after ETS, it would be coherent to maintain preload and systolic volume after ETS. Thus, it is possible to assume that there would be a decrease in cardiac output due to the reduction of HR. Then, suppression of the adrenergic stimulus could imply increase in oxygen extraction due to increased selective blood flow to the heart and muscles in activity. The reduction of the rate pressure product corroborates this hypothesis, characterizing a possible explanation for the maintenance of functional and metabolic capacity after ETS, despite the reduction in HR. However, the gas 
exchange threshold, a parameter that demonstrates changes locally in the muscle, did not suffer significant variation, opposing the theory of an increase in blood flow and availability of oxygen in muscles and corroborating another mechanism responsible for maintaining functional capacity: the increase in the ejection fraction (EF) [11].

The increase in EF would be explained by a possible increase in preload, due to the sinus reduction of HR originated by ETS, implying an increase in the preload, offsetting possible deleterious effects of cardiac contractility due to neural ablation [11], explained again by the Frank-Starling mechanism, in which cardiomyocyte strain provides greater contraction force by altering the degree of overlap between actin and myosin within the sarcomere.

Despite the results presented, we should take into account that the patients in the studies exhibit palmar or axillary hyperhidrosis, a condition that already presents a basal sympathetic hyperactivity. Such hyperactivity is not restricted only to the sweat glands, its systemic action can be demonstrated by increased heart rate at rest and during exercise, its lower variation between rest and maximal exertion, and vasodilation in the upper limbs (responsible for increased temperature and flushing). Thus, these are patients with a higher baseline heart rate than expected for age. For this reason, the results found in the studies may not be found in healthy individuals [13].

The results found in the study should be evaluated with parsimony given the small number of studies found in our search. Although the authors present results with statistical significance of $5 \%$, not all alterations have a definitive explanation, which justifies the need for further studies for the subject to be better clarified.

\section{Conclusions}

It is concluded that endoscopic thoracoscopic sympathectomy presents, as main cardiovascular effect, the reduction of heart rate, present in all studies evaluated by this systematic review regardless of the method used for evaluation or its chronology.

Despite the reduction in HR, there was an improvement in myocardial physical conditioning and maintenance of functional capacity, proven by increased oxygen pulse and reduction of the rate pressure product, as well as maintenance of Wmax, peak $\mathrm{VO}_{2}$ and $\mathrm{VO}_{2}$.

Several hypotheses are raised to justify the improvement of the functional capacity of the heart, such as a possible increase in preload, improvement of blood flow to the heart, increased oxygen uptake capacity or an increase in the ejection fraction. Each hypothesis is supported by the existence of physiological compensation mechanisms, but they are speculative, since the studies did not directly evaluate some important parameters directly related to these hypotheses.

There was disagreement in the articles between the presence of HR reduction during physical exertion and at rest or only during exertion. The sympathetic predominance of cardiac response to exertion would explain its postoperative 
alteration but would not explain it during rest. On the other hand, it is advocated that the heart rate is partially controlled by sympathetic activity even during rest, which is why interruption of sympathetic ganglia results, unexpectedly, in the reduction of heart rate both at rest and during exertion.

The evidence found should be evaluated sparingly, since these are studies conducted with a small number of patients and presenting a condition of basal sympathetic hyperactivity, so that the alterations found may not be reproducible in a population of healthy individuals.

To elucidate the real mechanisms involved in the maintenance of myocardial function, and even its improvement, it is necessary to develop further studies that directly evaluate cardiac output and arteriovenous difference in individuals without previous conditions of basal sympathetic hyperactivity. Once this mechanism is clarified, ETS can be studied as treatment or prophylaxis in patients at high risk for intractable angina, ventricular tachycardia, long QT syndrome, and vagal syndrome.

\section{Conflicts of Interest}

The authors declare no conflicts of interest regarding the publication of this paper.

\section{References}

[1] Kauffman, P. (2007) Simpatectomia torácica por videotoracoscopia para tratamento da hiperidrose primária. Jornal Brasileiro de Pneumologia, 33, 1-3.

https://doi.org/10.1590/S1806-37132007000300001

[2] Cavalcante, J.F., Alberto, C., Araújo, A., Netto, M.X., Edênio, F., Costa, R., et al. (2005) Efeitos da simpaticotomia endoscópica sobre as artérias carótidas e vertebrais na terapêutica cirúrgica da hiperidrose primária. Acta Cirúrgica Brasileira, 20, 101-106. https://doi.org/10.1590/S0102-86502005000700018

[3] Gilliland, S. and Brainard, J. (2015) Postoperative Noninvasive Ventilation Following Cardiothoracic Surgery: A Clinical Primer and Review of the Literature. Seminars in Cardiothoracic and Vascular Anesthesia, 19, 302-308. https://doi.org/10.1177/1089253215572699

[4] Britto, R.R. (2006) Uma Normatização Brasileira Six Minute Walk Test-A Brazilian Standardization. Fisioterapia em Movimento, 19, 49-54.

[5] Stein, R., Rodrigues, R., Castro, T., Gil, C. and Araújo, S. (2003) Normatização de Técnicas e Equipamentos para Realização de Exames em Ergometria e Ergoespirometria. Arquivos Brasileiros de Cardiologia, 80, 457-464. https://doi.org/10.1590/S0066-782X2003000400011

[6] Haddad, A. (2008) Valores de Referência para o Teste Cardiopulmonar para Homens e Mulheres Sedentários e Ativos. Arquivos Brasileiros de Cardiologia, 96, 54-59.

[7] Rf, S. and Mc, E.M. (2007) Estudos De Revisão Sistemática: Um Guia Para Síntese. Revista Brasileira de Fisioterapia (São Carlos), 11, 83-89.

[8] (IEP-HCor) AMB, (IEP-HCor) MFF, (IEP-HCor) ABC, (IEP-HCor) OB (2012) Diretrizes Metodológicas-Elaboração de revisão sistemática e metanálise de ensaios clínicos randomizados.

[9] Moher, D., Shamseer, L., Clarke, M., Ghersi, D., Liberati, A., Petticrew, M., et al. 
(2015) Preferred Reporting Items for Systematic Review and Meta-Analysis Protocols (PRISMA-P) 2015 Statement. Systematic Reviews, 4, 1.

https://doi.org/10.1186/2046-4053-4-1

[10] Kingma, R., TenVoorde, B.J., Scheffer, G.J., Karemaker, J.M., Mackaay, A.J.C., Wesseling, K.H., et al. (2002) Thoracic Sympathectomy: Effects on Hemodynamics and Baroreflex Control. Clinical Autonomic Research, 12, 35-42. https://doi.org/10.1007/s102860200008

[11] Inbar, O., Leviel, D., Shwartz, I., Paran, H. and Whipp, B.J. (2008) Thoracic Sympathectomy and Cardiopulmonary Responses to Exercise. European Journal of Applied Physiology, 104, 79-86. https://doi.org/10.1007/s00421-008-0784-9

[12] Ponce González, M.A., Serdá, G.J., Suarez, P.R., Perez-Peñate, G., Gilart, J.F. and Navarro, P.C. (2010) Long-Term Cardiopulmonary Function after Thoracic Sympathectomy: Comparison between the Conventional and Simplified Techniques. The Journal of Thoracic and Cardiovascular Surgery, 139, 405-410.

https://doi.org/10.1016/j.jtcvs.2009.05.011

[13] Fiorelli, A., D’Aponte, A., Canonico, R., Palladino, A., Vicidomini, G., Limongelli, F., et al. (2012) T2-T3 Sympathectomy versus Sympathicotomy for Essential Palmar Hyperhidrosis: Comparison of Effects on Cardio-Respiratory Function. European Journal of Cardio- Thoracic Surgery, 42, 454-461. https://doi.org/10.1093/ejcts/ezs071

[14] Fiorelli, A., Messina, G., Chiodini, P., Costanzo, S., Viggiano, A., Monda, M., et al. (2017) Cardiac Autonomic Changes after Thoracic Sympathectomy: A Prospective, Randomized Study. The Annals of Thoracic Surgery, 103, 216-224. https://doi.org/10.1016/j.athoracsur.2016.10.055

[15] Kawamata, Y.T., Kawamata, T., Omote, K., Homma, E., Hanzawa, T., Kaneko, T., et al. (2004) Endoscopic Thoracic Sympathectomy Suppresses Baroreflex Control of Heart Rate in Patients with Essential Hyperhidrosis. Anesthesia \& Analgesia, 98, 37-39. https://doi.org/10.1213/01.ANE.0000094984.90178.33 